\title{
GSI Maps - Showcase of National Geospatial Data
}

\author{
Kaito Kamimura ${ }^{\text {a, * }}$ \\ ${ }^{a}$ Geospatial Information Authority of Japan, Ibaraki, Japan, kamimura-k96ns@mlit.go.jp \\ * Corresponding author
}

Keywords: Web Maps, Utilizing Geospatial Information

\section{Abstract:}

Geospatial Information Authority of Japan (GSI), a special organization of the Ministry of Land, Infrastructure, Transport and Tourism (MLIT), operates web maps "GSI Maps" (https://maps.gsi.go.jp/) (Figure 1). GSI Maps is the showcase of geospatial information developed by GSI and can be used with various devices and web browsers. GSI Maps is one of GSI's important efforts to realize a society that everyone can get and utilize geospatial information anytime, anywhere.

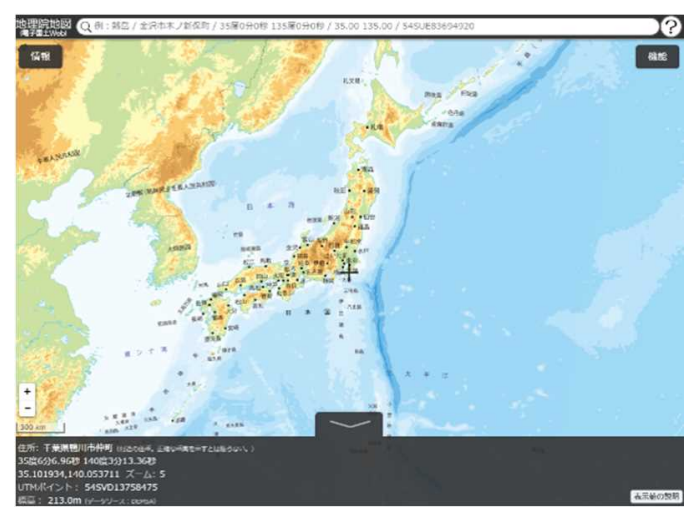

Figure 1. GSI Maps

GSI develops various geospatial information such as topographic maps, old and latest aerial photographs, thematic maps including land condition maps and active fault maps and disaster information (Figure 2). GSI provides these information as "GSI Tiles" to the public. The format of GSI Tiles is slippy map tilenames (XYZ) (https://wiki.openstreetmap.org/wiki/Slippy_map_tilenames). This idea reduces the load on operating GSI Maps since users do not need to download all the maps, but only the data that they browse.
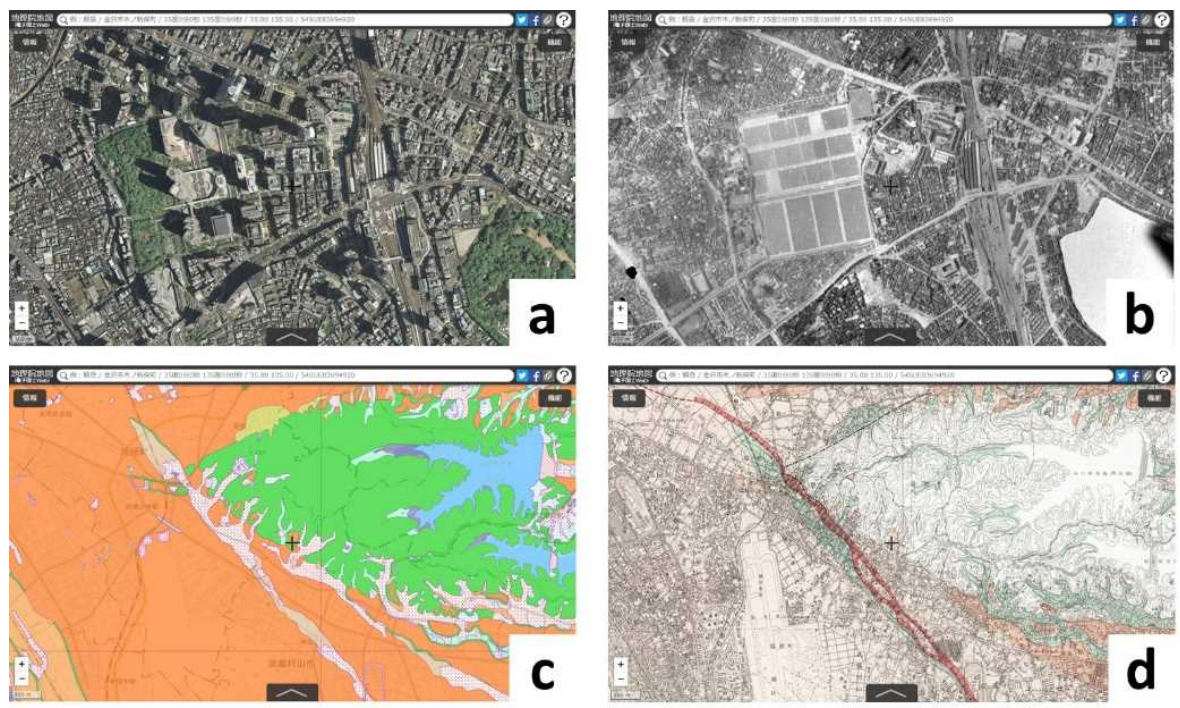

Figure 2. Examples of geospatial information on GSI Maps: latest (a) and old (b) aerial photograph, land condition map (c) and active fault map (d) 
GSI Maps enables users to overlay various GSI Tiles on web browsers. It also enables various geospatial information to be displayed in 3D view on web browsers using digital elevation model tiles (Figure 3 (a)). In addition, GSI Maps has a lot of functions for browsing and utilizing geospatial information. For example, users can see the elevation, longitude / latitude and the address of the center of the map, and can create a topographic profile and a color-changeable relief map (Figure 3 (b)).
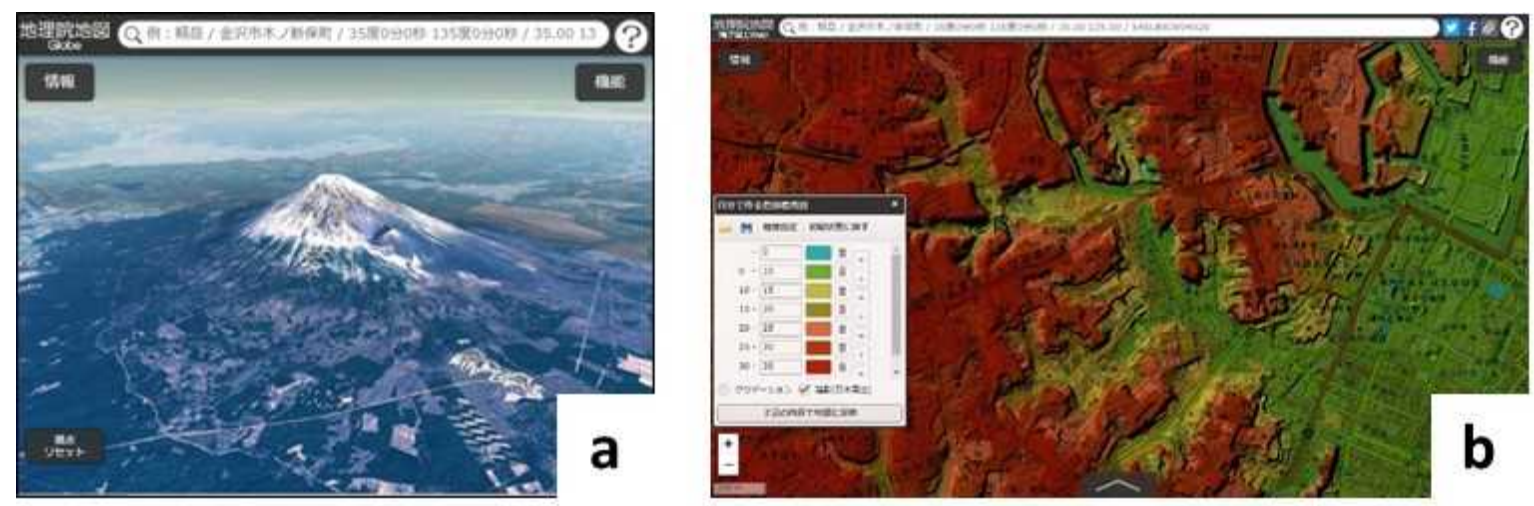

Figure 3. 3D display function (a) and color-changeable relief map (b) of GSI Maps

GSI focuses on providing disaster information to the public via GSI Map. In July 2018, a heavy rain disaster occurred in a wide area of western Japan. GSI developed various geospatial data and published them via GSI Maps immediately after the disaster, such as aerial photographs of the affected areas, provisional inundation depth map, and landslide distribution map. Also, in September 2018, big earthquake struck the eastern Iburi Subprefecture in southern Hokkaido and caused massive landslides and liquefaction phenomena. When GSI introduced comparison of aerial photographs before and after the landslides caused by the earthquake via GSI Maps, it brought great response by users, and picked up in TV news programs (Figure 4). Furthermore, GSI Maps also released the 3D earthquake source fault model estimated based on the diastrophism observed by InSAR (Interferometric Synthetic Aperture Radar) and GNSS (Global Navigation Satellite System) positioning. Disaster Information makes many people recognize the danger of disasters and the importance of preparedness, and the number of page views of GSI Maps increases greatly in the event of disasters.

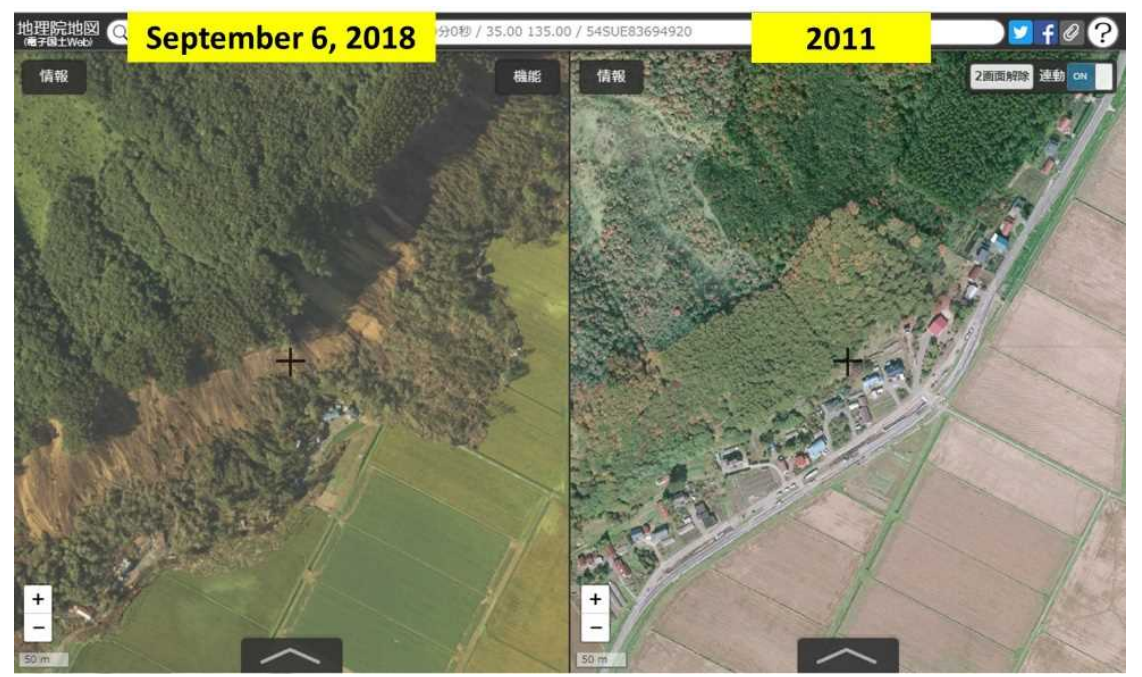

Figure 4. Comparison of aerial photos before and after landslides caused by The 2018 Hokkaido Eastern Iburi Earthquake using two screens display function of GSI Maps

In addition, GSI supports geography education and GSI Maps is expected as an important tool. As mentioned above, GSI Maps has a lot of information and functions for understanding geography, furthermore, is available for free with various devices and web browsers. Those features encourage GSI Maps being used in geography education. Students may search characteristic landform in Japan on GSI Maps, and watch videos of floods, etc. It is expected to help students understanding topography and encourage their interest in geography by using GSI Maps.

GSI Tiles have been provided in raster format so far, in FY2019 GSI will launch vector tiles that computers can read the contents of. By adopting them, various map expressions could be made according to the users' purpose. For example, users can hide some features and emphasize others. GSI promotes the use of maps in various fields by publishing various geospatial information as vector tiles. 